\title{
Shaking Table Test Study of Rock Falls of Slope Based on Orthogonal Design
}

\author{
Bo SONG, Miao SHUANG \\ School of Civil and Resource Engineering \\ University of Science and Technology Beijing \\ Beijing,China \\ e-mail: songbo@ces.ustb.edu.cn, shuangmiao204@163.com
}

\begin{abstract}
For sandy slope, size of rock fall, groundwater level and type of site are all important factors which have significant influences on the movement characteristics of rock falls. To obtain the importance of each factor, orthogonal analysis was studied and shaking table test was drawn up. In the tests, average acceleration was chosen to be as the evaluation index, and three important factors were discussed. It is shown that size of rock fall is the main factor, the second is type of site, and the third is groundwater level. The average acceleration is the maximum when the rock fall diameter is $100 \mathrm{~mm}$ and the groundwater level is $0.7 \mathrm{~m}$ and the earthquake wave is T1-II-1; the minimum is when the rock fall diameter is $40 \mathrm{~mm}$ and the groundwater level is $0.7 \mathrm{~m}$ and the earthquake wave is T2-II-1. Analysis results provide the bombardment energy for the potential slope rock fall prevention. It is important and helpful to the protection design of structures at the foot of slope.
\end{abstract}

Keywords-sandy slope; rock falls; shaking table test; orthogonal design

\section{INTRODUCTION}

With rapid economic development, western region is becoming main areas of high-speed railway construction in China. However, the rail construction faces many difficult problems, such as complex terrain environment, wide cover of Aeolian sandy soil, etc. Besides western region there is a lot of sandy soil along the existed high-speed rail, especially the wetland areas. For sandy slope, the top of slope will be cut into different soil blocks when soil contacts with atmospheric, raining water, biological, physical and chemical change. Integrity of the slope is damaged and broken. The collapse of slope will happen under earthquake, which is a serious threat to the safety of the existed structures at the foot of slope.

Researchers have made a series of analysis for the collapse of rock falls both at home and abroad. Huang Runqiu[1] analyzed 6 influential factors including onset style of rolling rock, feature of overburden and vegetation, gradient of slope,length of slope,shape of rolling rock and mass of rolling rock based on site experiment of rolling rock. Zhang Guangcheng[2] studied the characteristics and influence factors of restitution coefficient of rock fall collision by the field tests. Combining with data analysis and field survey, Andrea[3] put forward the quantitative method of probabilistic risk of rock falls resulted from earthquake. Hunger[4] gave a suggestion about the reachable area range of rock fall movement according to the survey of slope collapse. Hou Tianxing[5] studied the calculation method based on impulse theorem to determine impact force of rock falls on structures.

Above all, the existed study of the slope collapse is more about mechanism of rock fall collapse, motion characteristics, field tests. There is little about various factors that influence on motion characteristics, such as seismic, groundwater level, etc. in the research. In this paper, based on different sizes of rock falls, different groundwater levels and types of sites, shaking table test was carried out to study the influence on rock fall movement of three factors.

Based on CK162 + $075 \sim$ CK163 + 075 section of ZhunShuo railway, the typical cutting section is studied and the type of soil is sandy soil. The slope length is $17 \mathrm{~m}$ and slope height is $12 \mathrm{~m}$, as shown in Figure 1.

The size of model is determined by the size of shaking table and sand box. And the size of working plat is 1.5 square meters and the sand box is $1 \mathrm{~m}$ (width $) \times 2 \mathrm{~m}($ length $) \times 1.5 \mathrm{~m}$ (height). For the slope model, geometrical similarity coefficient is $1 / 24$.
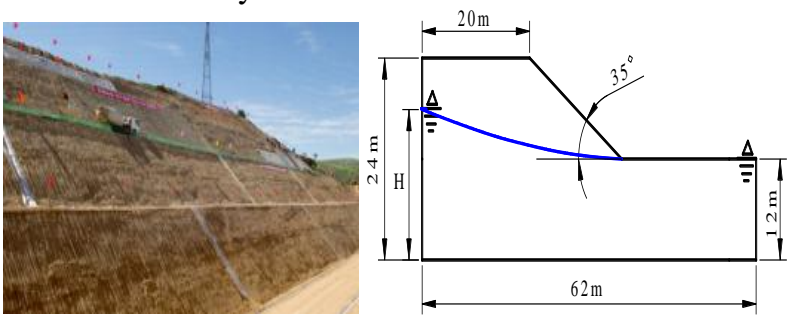

Figure 1. Zhun-Shuo railway and the simplified model of slope.

\section{TEST SCHEME DESIGN}

\section{A. Shaking Table Test Model of Slope Rock Fall}

Slope model is simulated with homogeneous and simplified model. Slope angle is $35^{\circ}$ and slope height is $0.5 \mathrm{~m}$. The slope is sandy soil (clay content $\geq 40 \%$ ), and the soil is hard and is easy to condense into blocks. Rock fall diameters are $20 \mathrm{~mm}, 30 \mathrm{~mm}, 40 \mathrm{~mm}, 50 \mathrm{~mm}, 60 \mathrm{~mm}, 80 \mathrm{~mm}$ and $100 \mathrm{~mm}$ respectively, which are used to research the influence of rock fall sizes on the collapse distance. The slope model and rock falls are shown in Figure 2. Physical parameters of slope are obtained by shear test, as shown in Table 1. 
TABLE I. PHYSICAL PARAMETERS OF SANDY SOIL

\begin{tabular}{cccccc}
\hline Property & Dry density & Cohesion & Frictional & Relative & Uniformity \\
& $\left(\mathrm{g} / \mathrm{cm}^{3}\right)$ & $(\mathrm{kPa})$ & angle $\left({ }^{\circ}\right)$ & density & coefficient \\
Sandy slope & 1.62 & 7.23 & 35 & 0.57 & 4.03 \\
\hline
\end{tabular}

\section{B. Test Instruments And Loading Conditions}

The test is carried out on the hydraulic one-way shaking table (ES-15/KE-2000). Shaking table test consists of hydraulic control, oil pump station, and horizontal shaking table. The main technical targets of the shaking table test are as follows: maximum test load is $5000 \mathrm{~kg}$, maximum acceleration is $20 \mathrm{~m} / \mathrm{s}^{2}$, rated speed is $0.5 \mathrm{~m} / \mathrm{s}$. The size of working table is 1.5 square meters.

El Centro and different ground seismic waves (T1-II-1, T2-II-1) are chosen to analyze, as shown in Table 2. Earthquake excitations are one-way input.

TABLE II. TEST CONDITIONS

\begin{tabular}{ccc}
\hline Test conditions & Type of earthquakes & Peak acceleration $(\mathbf{g})$ \\
T01 & T1-II-1 & 0.2 \\
T02 & T2-II-1 & 0.2 \\
El-01 & El Centro & 0.2 \\
\hline
\end{tabular}

\section{TEST RESULTS AND ANALYSIS}

\section{A. Influence of Groundwater Level on Rock Fall Distance under Earthquakes}

Rock falls of different diameters are chosen to study the influence on rock fall distance when groundwater levels are $0.6 \mathrm{~m}, 0.7 \mathrm{~m}$ and $0.8 \mathrm{~m}$, respectively.

As shown in Figure 3, with the increase of groundwater level, the distances of different diameters of rock falls show the trend of increase under different earthquakes. When the groundwater level is the same, the distances of rock falls increase with the increase of rock fall diameters. The main reason is initial velocity increase with the increase of groundwater level. Then the increase of initial velocity results in high kinetic energy and the increase of distance.

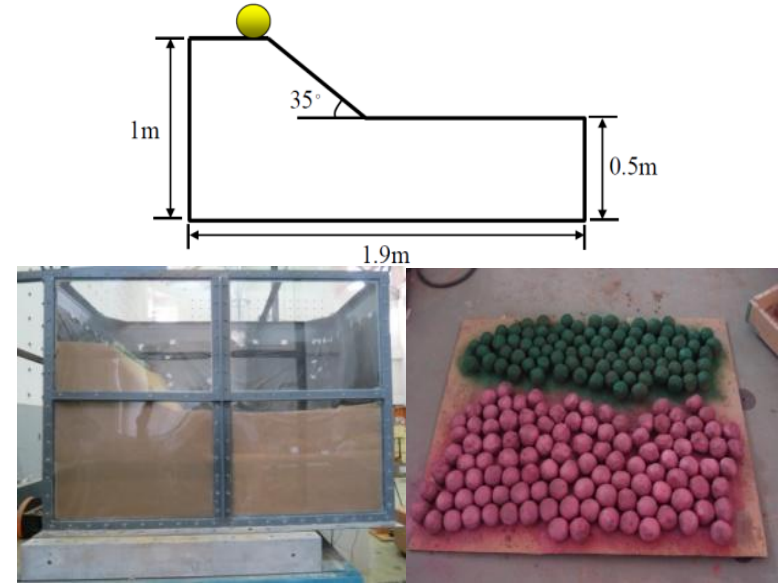

Figure 2. Slope model and rock falls.

\section{B. Analysis of Motion Characteristics of Rock Fall}

The initial velocity of rock falls at the top of slope is given by the shaking table test. The initial velocity under far field earthquake is greater than that under near field earthquake and the initial velocity under El Centro is the least, as shown in Figure 4.

Assume that slope is simplified as a single-line slope. The average acceleration can be derived based on kinematic formulas. According to the law of conservation of energy, collapse distance of rock falls can be given as following:

$$
\frac{1}{2} m v_{z}^{2}=N L f
$$

Where $L$ is the distance from the resting position to the foot of slope; $N$ is the positive pressure on the ground when rock falls move on a horizontal plane; $f$ is the rolling friction factor and can be valued as is 0.4 for the spherical rock fall based on test; $v_{z}$ is the velocity after refraction of the slope.

\section{Sensitivity Analysis of Factors}

The motion characteristics of rock fall are influenced by various factors when it moves on the surface of slope. If it can be determined which factor has the greater influence and which combination of factors has the greater influence, the factor which influence is greater will be focused on in slope disposal and design. Based on that, the slope treatment scheme and design will be safer and more economical. So the orthogonal experiment design is applied to sensitivity analysis of various factors.

\section{Principle of Orthogonal Test Method}

Orthogonal test design means that the typical minority are chosen from all testing schemes. Fewer tests are used to analyze testing results and find the optimal solution.

Assume that A, B, C, etc. separately represent different factors, $\mathrm{i}$ is the level of every factor, and $P_{i j}$ is the value of level $\mathrm{i}$ for factor $\mathrm{j}$. The experimental result $Q_{i j}$ can be obtained under $P_{i j} \cdot Q_{i j k}$ (n experimental results) can be gained by $n$ experiments under.

$$
K_{i j}=\sum_{k=1}^{n} Q_{i j k}
$$
$A_{i}$.

Where $K_{i j}$ is the statistical parameter of level $\mathrm{i}$ for factor

Range $R_{i}$ is the significant parameter of evaluation factors, which can be written as:

$$
R_{j}=\max \left\{\overline{K_{1 \mathrm{j}}}, \overline{K_{2 \mathrm{j}}}, \overline{K_{3 \mathrm{j}}}, \cdots, \overline{K_{\mathrm{ij}}}\right\}-\min \left\{\overline{K_{1 \mathrm{j}}}, \overline{K_{2 \mathrm{j}}}, \overline{K_{3 \mathrm{j}}}, \cdots, \overline{K_{\mathrm{ij}}}\right\}
$$

The order of range is the order of impact of every factor on test results. 

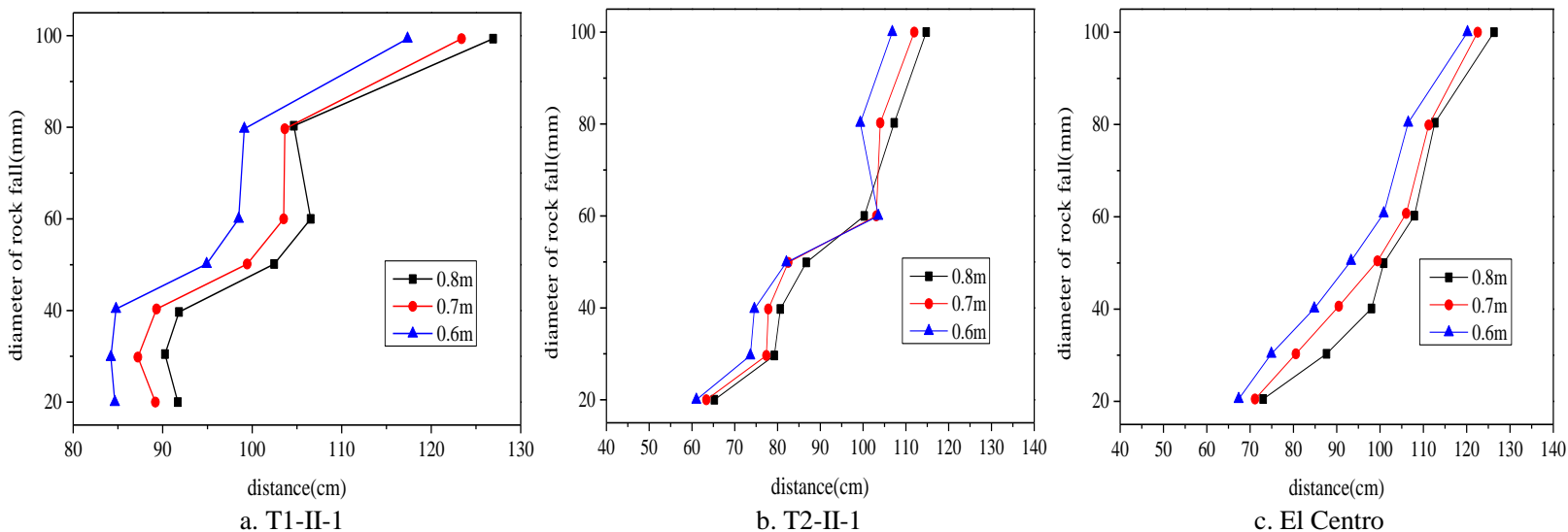

Figure 3. Influence of groundwater level on rock fall distance under different earthquakes.

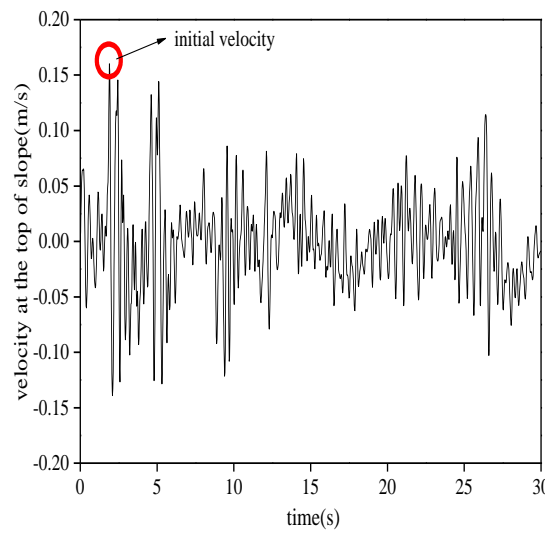

a. T1-II-1

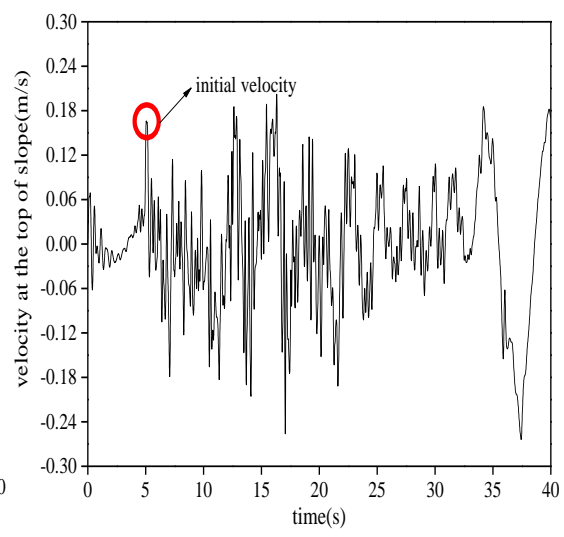

b. T2-II-1

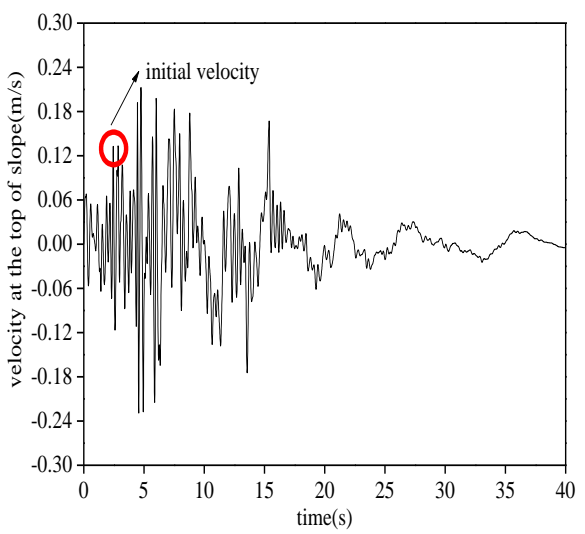

c. El Centro

Figure 4. Initial velocity at the top of slope under different earthquakes.

\section{E. Orthogonal Test Design}

Rock fall movement is affected by many factors. It is not realistic to consider all the factors in a test. Therefore three factors are selected, including the size of rock falls, the groundwater level and the type of site as shown in Table 3.

Range of vacant column is $R_{j}=0.76$. The relative error is $7 \%$ which can meet the requirements.

\section{F. Range Analysis}

(1) Maximum average acceleration is No.8 test when the test combination scheme is $\mathrm{A} 3 \mathrm{~B} 2 \mathrm{C} 1$. Minimum average acceleration is No.2 test when A1B2C2.

(2) Based on the shaking table test, average acceleration of rock fall can be obtained under the different combination of various factors, and the experiment results by rang analysis are analyzed, shown in Figure 5 and Figure 6.

In one experiment, influence of various factors is the main one time. It's obvious that if a factor with different levels has a greater effect on average acceleration and the range is bigger, this factor is as the main. On the contrary, if less and smaller, this factor is secondary. More widespread factor is the main and less is minor as reflected in Figure 5 and Figure 6. The influential order of three factors on the average acceleration is $\mathrm{A}, \mathrm{C}$ and $\mathrm{B}$.

\section{CONCLUSION}

For sandy slope, it is shown that size of rock fall is the main factor, the second is type of site, and the third is groundwater level. The average acceleration is maximal when the rock fall diameter is $100 \mathrm{~mm}$ and the groundwater level is $0.7 \mathrm{~m}$ and the earthquake wave is T1-II-1; the average acceleration is minimal when the rock fall diameter is $40 \mathrm{~mm}$ and the groundwater level is $0.7 \mathrm{~m}$ and the earthquake wave is T2-II-1. With the increase of groundwater level, the distances of different diameters of rock falls show the trend of increase under different earthquakes. The collapse distance of rock fall under far field earthquake is greater than that under near field earthquake. It shows that energy of rock fall is larger and the threat is more for buildings at the foot of slope under far field earthquake. 

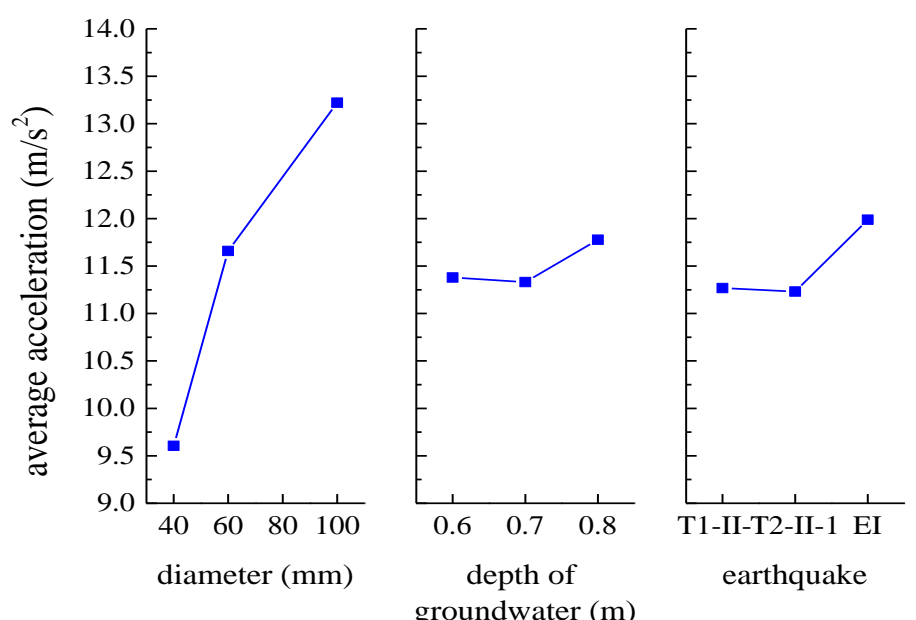

Figure 5. Relationship between acceleration and all influence factors.

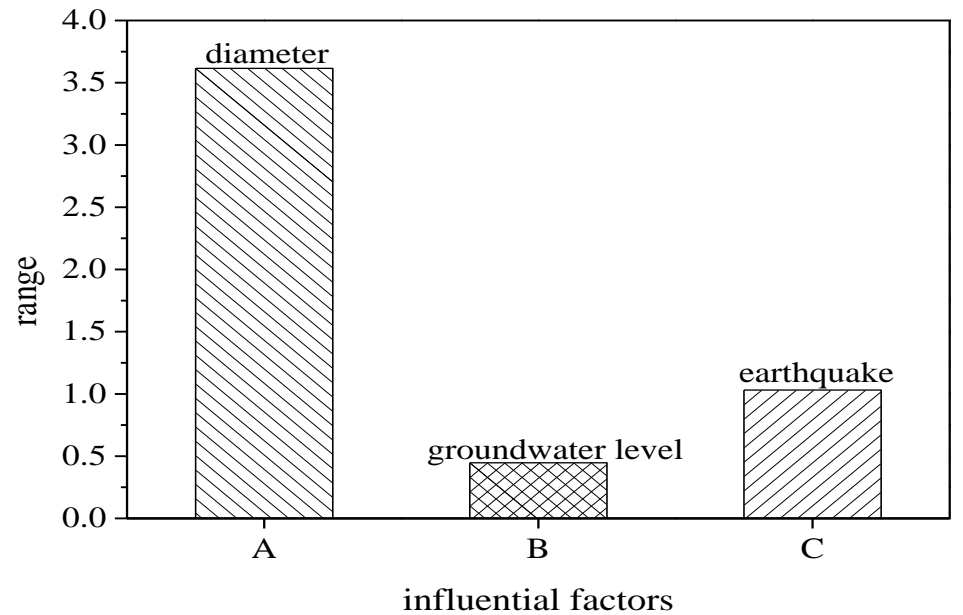

Figure 6. Range of parameters.

TABLE III.

FACTORS AND LEVELS OF ORTHOGONAL EXPERIMENT

\begin{tabular}{|c|c|c|c|c|c|c|c|}
\hline Levels & \multicolumn{2}{|c|}{$A($ Diameter $/ \mathrm{mm})$} & \multicolumn{3}{|c|}{ B(Groundwater level /m) } & $e l / m)$ & C(Type of \\
\hline 1 & \multicolumn{2}{|l|}{40} & \multicolumn{3}{|r|}{0.6} & & $\mathrm{~T} 1$ \\
\hline 2 & \multicolumn{2}{|l|}{60} & \multicolumn{3}{|r|}{0.7} & & $\mathrm{~T} 2$ \\
\hline 3 & \multicolumn{2}{|l|}{100} & \multicolumn{3}{|r|}{0.8} & & El \\
\hline & \multicolumn{3}{|c|}{ TABLE IV. } & \multicolumn{3}{|c|}{ ANALYSIS AND COMPUTATION } & \\
\hline & Test number & $1(A)$ & $2(B)$ & $3(C)$ & 4 & Average acceleration & $\left(m / s^{2}\right)$ \\
\hline & 1 & 1 & 1 & 1 & 1 & 9.37 & \\
\hline & 2 & 1 & 2 & 2 & 2 & 8.61 & \\
\hline & 3 & 1 & 3 & 3 & 3 & 10.84 & \\
\hline & 4 & 2 & 1 & 2 & 3 & 11.47 & \\
\hline & 5 & 2 & 2 & 3 & 1 & 11.73 & \\
\hline & 6 & 2 & 3 & 1 & 2 & 11.78 & \\
\hline & 7 & 3 & 1 & 3 & 2 & 13.30 & \\
\hline & 8 & 3 & 2 & 1 & 3 & 13.65 & \\
\hline & 9 & 3 & 3 & 2 & 1 & 12.71 & \\
\hline & $\mathrm{K}_{2 \mathrm{j}}$ & 28.82 & 34.14 & 34.80 & 33.80 & $=103$ & \\
\hline & $\mathrm{K}_{\mathrm{z}_{\mathrm{j}}}$ & 34.98 & 33.99 & 32.78 & 33.69 & & \\
\hline & $\mathrm{K}_{\mathrm{Y}_{1}}$ & 39.67 & 35.33 & 35.88 & 35.96 & & \\
\hline & $\overline{\mathrm{K}}_{2 \mathrm{i}}$ & 9.61 & 11.38 & 11.60 & 11.27 & $\frac{1}{9} \sum_{y_{i}}=11$ & \\
\hline
\end{tabular}




\section{REFERENCES}

[1] Huang R, Liu W. (2009). "In-situ test study of characteristics of rolling rock blocks based on orthogonal design." Journal of Rock Mechanics and Engineering, Vol 28(5): 882-891.

[2] Zhang G, Xiang X, Tang H. (2011). "Field test and numerical calculation of restitution coefficient of rockfall collision." Journal of Rock Mechanics and Engineering, Vol 30(6): 1266-1273.

[3] Valagussa A, Frattini P, Crosta G B. (2014). "Earthquake-induced rockfall hazard zoning." Engineering Geology, Vol 182(2014): 213-
225.

[4] Hungr O D, Evans S G. (1988). "Engineering evaluation of fragmental rockfall hazards." Proceedings of the 5th International Symposium on Landslides and Engineered Slopes, 685-690.

[5] Hou T, Yang X, Huang C, et al. (1988). "A calculation method based on impulse theorem to determine impact force of rockfall on structure." Journal of Rock Mechanics and Engineering, Vol 34(Supp.1): 3116-3122. 